professional achievement in their speciality of which members of a Royal College can be proud.

In 1989 the Royal College of General Practitioners (RCGP) introduced Fellowship by Assessment which is a patient-centred assessment, based on a visit to the workplace of the applicant. The RCGP (1995) has published a list of essential criteria, each of which must be achieved, and each one of which is patient based. The assessment visit is undertaken by three established Fellows, increasingly themselves Fellows by Assessment, and doctors achieving this standard have reported gaining very considerable personal and professional satisfaction from doing it (Price, 1995).

This certainly prevents the Fellowship becoming a "self-perpetuating oligarchy which will tend to exclude those who have a low profile on the national regional scene but may still be doing good work". The RCGP system is open to every member of five years' standing and is based entirely on good work in the locality. Regional and national service is irrelevant. It is currently available as an alternative route to the RCGP Fellowship and Dr Moliver and other readers may find it of interest.

Price, A. (1995) FBA the Cornish way - a group experience. In Fellowship by Assessment. Occasional Paper 50. 2nd edition. London: RCGP.

Royal COLlege of General Practitioners (1995) Fellowship by Assessment. Occasional Paper 50. London: RCGP.

DENIS PEREIRA GRAY, Director, Postgraduate Medical School, University of Exeter

\section{Non-conversion of Section 5(2)}

Sir: The Commission's report (Mental Health Act Commission, 1987) expressed concern about the use of Section 5(2) as an independent power of short-term detention for $\mathbf{7 2}$ hours rather than as a measure to provide authority to detain while an assessment for compulsory admission may be made. Incorrect use of Section 5(2) may result in the hospital being sued for damages, for false imprisonment and for negligence. Three published studies (Mason \& Turner, 1994; Joyce et al, 1991; Pourgourides et al, 1992) raised questions about the appropriate use of Section 5(2).

In an extensive review of a much larger sample size, all applications of Section 5(2) of the Mental Health Act 1983 in North Cheshire between 1985-1995 were reviewed to examine general trends in its use and outcome. Between 19851995, there were 20601 admissions to Winwick Hospital, which serves the whole of North Cheshire, including 898 Section 5(2) applications. The conversion rate of Section 5(2) to other sections of MHA in this review was $\mathbf{5 7 \%}$, similar to that reported by Mason \& Turner, 55\% (1994); Pourgourides et al, 52\% (1992); and Joyce et al, $48 \%$ (1991).

In $20 \%$ of cases, an application for Section 2 was made at the same time as Section 5(2). Indications for Section 5/2 included aggresstve behaviour $(16 \%)$, deliberate self-harm and suicidal threats (34\%), and acute psychosis (44\%). The low conversion rate was probably due to the fact that most patients were involved in acute transient behavioural disturbance. Low conversion rate of Section 5(2) to other sections of MHA should not be taken as an indicator of the incorrect use of the order.

JOYCE. J., MORRIS, M. \& PALA, S. S. (1991) Section 5(2) audit. Psychiatric Bulletin, 16, 224.

MASON, P. \& TURNER R. (1994) Audit of the use of doctors holding power under section 5(2) of the MHA 1983. Health Trends, 26, 44-46.

MENTAL HEALTH ACT COMMISSION (1987) 2nd Biennial report 1985-1987. London: HMSO.

POURGOURIDES, C., PRASHER, V. P. \& OYEBODE, F. (1992) Use of Section 5(2) in clinical practice. Psychiatric Bulletin. 16. 14-16.

BONI IPARRAGIRRE and EMAD SALIB, Winwick Hospital, Warrington Community Health Care (NHS) Trust, Cheshire

\section{The Geoffrey Knight Unit has survived}

Sir: This Unit has provided a significantly decreased level of service during the past year. I can now inform readers that we remain available for referrals, and the Unit has now moved from the Brook General Hospital to the Maudsley Hospital, London.

The first problem was that the Greenwich NHS Trust unilaterally reduced our beds from eight to four. This saved money and, with some other savings, it was possible to buy an MR scanner. Unfortunately, this was second-hand and never functioned before it became obsolete. Then, at the end of 1994, we were told that radio-yttrium, which we used to produce the lesion for our stereotactic subcaudate tractotomy operation (Bridges et al, 1994), could no longer be supplied because we were the only users. There was a delay for modifications and we are now using radio-frequency to produce the lesion. While psychosurgery was halted, we continued to admit patients for trials of high dose and combined antidepressants (Bridges et al, 1995) which, our clinical experience has shown, has reduced the need for psychosurgery in recent years.

The situation at present is that out-patients are seen at the Maudsley Hospital, we have inpatients at the Bethlem Royal Hospital and beds are available to us on the neurosurgery wards at King's College Hospital. 